\title{
A EPISTEMOLOGIA DA PESQUISA QUALITATIVA ${ }^{1} / /$ Howard S. Becker ${ }^{2}$
}

\section{Palavras-chave}

Epistemologia / Pesquisa qualitativa e pesquisa quantitativa / Etnografia / Pesquisa de campo / Surveys

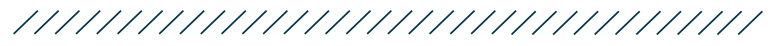

\section{Sumário}

1 "Qualitativo" e "quantitativo"

2 Algumas reflexões sobre a epistemologia

3 Por que acreditamos que existe uma diferença

4 Várias etnografias

50 ponto de vista do ator: precisão

60 mundo cotidiano: dando espaço ao inesperado

7 Descrição completa, descrição densa: observando as margens

8 Epílogo

9 Considerações adicionais

10 Referências

\section{Resumo ${ }^{3}$}

Este artigo discute questões relevantes à epistemologia da pesquisa qualitativa. Para tanto, discute-se e questiona-se a suposta dicotomia entre a pesquisa qualitativa e a quantitativa. Sustenta-se aqui que as semelhanças entre tais métodos são mais relevantes do que suas diferenças. Ambos os métodos procuram descrever a realidade social e têm a mesma base epistemológica, ainda que com ênfase em questões diferentes. Para esclarecer a origem de tal dicotomia, menciona-se a origem da epistemologia como disciplina e seu caráter filosófico. Finalmente, as especificidades e vantagens da pesquisa qualitativa, especialmente a etnografia e a pesquisa de campo, são discutidas por meio da análise de alguns aspectos de tais formas de observação da realidade social: o ponto de vista do ator, a observação do mundo cotidiano e a descrição completa e densa.

\footnotetext{
1. Este artigo foi originalmente publicado em inglês pela University of Chicago Press, em 1986. Ele apareceu como capítulo do livro Ethnography of Human Development: Context and Meaning in Social Inquiry (organizado por Richard Jessor, Anne Colby e Richard A. Schweder), com o título "The Epistemology of Qualitative Research". Agradecemos à editora e ao autor pela autorização para publicação desta versão em português. Tradução de Julia Gitahy da Paixão, revisão técnica de José Roberto Franco Xavier.

2. Howard S. Becker é um renomado sociólogo americano, que fez grandes contribuições à sociologia da delinquência, à sociologia da arte e à sociologia da música. Também escreveu bastante sobre métodos de pesquisa e a escrita acadêmica. Terminou seu doutorado em sociologia na Universidade de Chicago em 1951 e depois disso foi professor em várias instituições superiores. Primeiro, começou como instrutor de sociologia na University of Chicago e depois foi pesquisador associado na Stanford University e finalmente se tornou professor de sociologia na Northwestern University em 1965 , tendo ali ficado até 1991 . Depois disso foi professor de sociologia e de música de 1996 a 1999 na University of Washington, quando se aposentou. Hoje ele vive entre São Francisco e Paris e ainda escreve e é músico.

3. Resumos e palavras-chave, em inglês e português, formulados pela tradutora.
} 


\section{THE EPISTEMOLOGY OF QUALITATIVE RESEARCH // Howard S. Becker}

\section{Keywords}

Epistemology / Qualitative and quantitative research / Ethnography / Field research / Surveys

\begin{abstract}
This article discusses questions that are relevant to the epistemology of qualitative research. In order to do so, the presumed dichotomy between qualitative and quantitative research is discussed and challenged. According to the author, the similarities between these methods are more relevant than its differences. Both methods strive to describe the social reality and thus have the same epistemological basis, even though they emphasize different questions. To shed light in such dichotomy, the author explores the origins of epistemology as a discipline and its philosophical character. Finally, the particularities and advantages of qualitative research are discussed, especially ethnography and field research, through an analysis of some of its main aspects for observing social reality: its focus on the point of view of the actor; the observation of the everyday world and the full and thick description.
\end{abstract}




\section{1 "Qualitativo" e "quantitativo"}

Ao discutir questões epistemológicas em ciências sociais é retoricamente inevitável comparar os métodos "qualitativos" e "etnográficos" com aqueles que são "quantitativos" e que usam "surveys". Em outras palavras, sempre acabamos comparando, no nosso imaginário, uma pesquisa de campo realizada em uma comunidade ou organização com uma pesquisa de survey desta mesma comunidade ou organização, feita por meio de questionários (respondidos pelos próprios sujeitos da pesquisa ou submetidos aos entrevistadores que os encontram apenas uma vez, munidos de um formulário impresso para ser preenchido). 0 próprio tema desta conferência presume tal distinção.

Presumindo que estas duas maneiras de pesquisar são baseadas em arcabouços e fundamentos epistemológicos diferentes nos leva a pensar na questão proposta pelos organizadores da conferência: "Qual é a epistemologia da pesquisa qualitativa?" Para mim, essa é uma questão estranha. Eu sou um intelectual descendente de Robert E. Park, o fundador da agora já conhecida Escola de Sociologia de Chicago. Park era um grande defensor do que hoje conhecemos como métodos etnográficos, mas ao mesmo tempo também era proponente dos métodos quantitativos, particularmente aqueles que conhecemos como ecológicos. Eu o acompanho nesse ponto, e para mim as semelhanças entre esses métodos são mais relevantes que suas diferenças. De fato, penso que os mesmos argumentos epistemológicos sustentam ambos os métodos.

Como isso é possível? Ambos os tipos de pesquisa tentam observar como a sociedade funciona, descrever a realidade social e também responder a questões específicas sobre a realidade social. Alguns cientistas sociais estão interessados em descrições muito genéricas, por meio de enunciados sobre classes inteiras de fenômenos. Outros estão mais interessados em compreender casos específicos, de que maneira esses enunciados genéricos funcionam num determinado caso. Mas, de qualquer forma, há muita sobreposição.

Esses dois tipos de trabalho colocam ênfase distinta na compreensão de casos histórica ou epistemolo- gicamente específicos, em oposição aos enunciados genéricos sobre a interação social. No entanto, um estilo de pesquisa é também interdependente do outro. Cada estudo de caso se apoia, explicita ou implicitamente, em algum enunciado geral; e cada enunciado geral supõe que a investigação dos casos particulares mostraria a aplicação do enunciado na prática. A despeito da ênfase diferente, tudo acaba num entendimento comum, não é?

Todavia, este tipo de ecumenismo claramente não resolve o problema, porque a pergunta não vai embora. Para destacar um exemplo familiar: mesmo que pesquisadores em educação façam pesquisas qualitativas perfeitamente boas há pelo menos 60 anos, eles ainda assim realizam encontros e debates periódicos, como este congresso, para discutir se tais pesquisas são legítimas ou não. $E$, se o são, por que o são. Obviamente deve haver alguma diferença epistemológica real entre estes dois métodos que possa explicar essa contínua inabilidade para se responder a essa questão.

\section{Algumas reflexões sobre epistemologia}

Vamos dar um passo atrás e questionar a epistemologia como disciplina. Como ela vê a sua tarefa? Que tipos de questões ela levanta? Como muitas outras disciplinas filosóficas, a epistemologia tipicamente se preocupa com o que "deve ser" ao invés do que "é", e resolve suas questões através da lógica de princípios e não por meio de pesquisa empírica. Em contrapartida, disciplinas empíricas têm se preocupado com a maneira como as coisas funcionam e não como elas devem funcionar, e resolvem suas questões empiricamente.

Alguns tópicos da discussão filosófica se transformaram em áreas de investigação empírica. Acadêmicos já estudaram biologia e física por meio da leitura de Aristóteles. A política, que é outra área que já foi controlada por filósofos, já foi também uma área na qual acadêmicos resolviam suas questões por meio do raciocínio lógico no lugar da pesquisa. Podemos assistir a áreas da filosofia, entre elas a epistemologia, passando por essa mesma transformação recentemente: desiste-se de pregar como as coisas devem ser e passa-se a observar como as coisas são realiza- 
das de fato.

A estética, por exemplo, era tradicionalmente o estudo de como distinguir a arte da não-arte e, mais especificamente, como distinguir a grande arte da arte ordinária. O seu impulso é negativo: a preocupação primordial é identificar candidatos que não mereçam o honorífico título de arte e assim manter tais impostores de fora. A sociologia da arte, o descendente empírico da estética, desistiu de fazer essa distinção entre o que deve ser e o que não deve ser chamado de arte. Em vez disso, ela descreve o que é feito sob tal nomenclatura. Parte dessa tarefa é exatamente revelar como o título honorífico de "arte" é disputado, quais ações tal disputa justifica e o que seus usuários conseguem fazer impunemente (ver Becker, 1982, p. 131-164).

A epistemologia tem sido uma disciplina também negativa, sobretudo preocupada em dizer o que você não deve fazer se quiser que sua atividade mereça o título de ciência, prevenindo assim que impostores sem mérito possam se apropriar de tal título. A sociologia da ciência, o descendente empírico da epistemologia, desistiu de tentar definir o que deve e o que não deve contar como ciência, e assim descreve o que as pessoas que afirmam estar produzindo ciência fazem, como o termo é disputado, e quais pessoas conseguem usar tal título impunemente (Latour, 1987).

Portanto, este artigo não é um sermão sobre como devemos fazer ciência, e o que não devemos fazer, e quais são os males que nos afetarão caso decidamos fazer coisas proibidas. Em vez disso, falo sobre como os etnógrafos têm produzido resultados confiáveis e críveis, especialmente aqueles resultados que continuam impondo respeito e convicção.

Para ser filosófico, tal tarefa é bem Aristotélica, de acordo com o plano da Poética que se incumbiu de não legislar sobre como a tragédia deve ser construída, mas, ao contrário, procurou observar o que era verdadeiro nas tragédias que evocavam compaixão e terror, produzindo assim catarse. Epistemólogos têm pretendido fazer tais análises Aristotélicas, mas o que se têm produzido se parece mais com sermões.

\section{Por que acreditamos que existe uma diferença?}

Duas circunstâncias parecem ter produzido as supostas diferenças entre a epistemologia qualitativa e a quantitativa, que parecem ser tão importantes nas ciências sociais. A primeira é que estes dois tipos de métodos tipicamente levantam questões um pouco diferentes no nível dos dados, a fim de produzir generalizações sobre a vida social. Os pesquisadores de surveys usam uma variante do paradigma experimental, procurando diferenças numéricas entre dois grupos de pessoas que diferem entre si de maneira interessante numa dimensão de atividade ou de contexto. Eles querem descobrir, por exemplo, se adolescentes com pais que tenham empregos com um status socioeconômico mais alto têm menores chances de cometer atos delinquentes ou não - uma diferença pela qual eles poderiam inferir que outras diferenças na experiência ou possibilidade poderiam "explicar" a delinquência. 0 argumento consiste em uma "explicação" de um ato baseado na lógica da diferença entre grupos com características diferentes (Abbot, 1992).

A minha intenção não é simplificar o que acontece nesse tipo de trabalho. A elaboração de tal lógica pode, e quase sempre é, muito mais complicada do que isso. Os pesquisadores podem se preocupar com o efeito da interação entre variáveis e como algumas variáveis condicionam as relações entre outras variáveis, tudo isso conspirando para uma figura complexa das circunstâncias da participação de alguém na delinquência.

Pesquisadores de campo, por sua vez, geralmente querem atingir algo bem diferente: a descrição da organização da atividade delinquente, uma descrição que compreendem na medida do possível a partir da sua observação da delinquência juvenil. Quem são as pessoas envolvidas na ação em questão? Quais eram as relações deles antes, durante e depois do evento? Quais são as relações deles com as outras pessoas que eles vitimizam? Quais são as relações deles com a polícia? E com a justiça de menores? Pesquisadores de campo também estão interessados na história dos eventos: como isso começou? O que aconteceu depois? E depois ainda? E como tudo isso acabou eventualmente se tornando em um ato de delinqu- 
ência ou uma carreira de delinquente? E como essa sequência de eventos depende da organização de toda esta outra atividade?

O argumento aqui reside na interdependência de muitos enunciados "mais-ou-menos provados". o ponto aqui não é provar, sem nenhuma dúvida, a existência de uma relação particular, mas sim de descrever um sistema de relações, de mostrar como as coisas interagem dentro de uma rede de influência múltipla ou suportam uma relação de interdependência ou qualquer coisa, a fimd e descrever as conexões entre as especificidades que o etnógrafo conhece pela própria virtude de "ter estado lá" (ver a descrição em Diesing, 1971). Ter estado lá produz uma convicção forte de que os variados eventos que foram observados estão todos conectados, o que não é insensato porque o que o pesquisador de campo observa não são variáveis ou fatores que precisam ser relacionados, mas sim pessoas fazendo coisas juntas de maneira manifestamente conexa. Afinal, são as mesmas pessoas e é somente a nossa análise que produz o abstrato e as variáveis discretas que usamos para que tudo faça sentido. Assim, a pesquisa de campo te deixa consciente do caráter construído destas variáveis (o que não quer dizer que não devemos nunca falar em variáveis e usá-las).

Uma segunda diferença que pode explicar o sentimento persistente de que os dois métodos diferem epistemologicamente é que, nas situações de coletas de dados dos pesquisadores de campo, muita informação é apresentada, mesmo que esses não a procurem e independentemente da sua vontade. Se um pesquisador faz um survey, ele vai saber de antemão toda a informação que pode ser coletada. Podem existir algumas surpresas nas conexões entre os itens medidos, mas não vai haver nenhum dado surpresa, ou seja, coisas que não foram perguntadas mas que foram coletadas de qualquer forma. Uma exceção parcial a isso pode ser o uso de questões abertas, mas tais questões não são usualmente inseridas nos questionários, de forma a não estimular um fluxo de dados não antecipados que sugiram novas variáveis. De fato, de acordo com o atual funcionamento das organizações de surveys, os entrevistadores são desestimulados a registrar dados não perguntados nos formulários (Peneff, 1988).
Em contraste, pesquisadores de campo não podem se isolar dos dados. Desde do momento em que eles "entram no campo" eles vão observar e ouvir coisas que devem ser registradas em seus cadernos de campo. E se eles são conscientes, ou experientes o suficiente, devem saber que eles têm que colocar tudo dentro dos seus registros, mesmo aquilo possa parecer inútil, e têm que continuar a fazer isso até que eles tenham certeza que não vão mais usar os dados sobre certos temas. Então, eles estão abertos a se tornarem conscientes de coisas que não foram antecipadas e que podem ter influência no seu tema de pesquisa. Eles têm uma expectativa de continuar a acrescentar variáveis e ideias aos seus modelos. E, de alguma forma, essa é a essência do seu método.

\section{$4 \quad$ Várias etnografias}

Há vários trabalhos que são chamados de etnografias e que não são iguais entre si; e essa diferença pode decorrer de detalhes epistemológicos. Na parte seguinte deste artigo, concentro-me nas tradições mais antigas (por exemplo, a observação participante, as entrevistas abertas ou não-estruturadas) e não nas versões mais recentes e na moda (por exemplo, a leitura hermenêutica de textos), mesmo que as versões mais novas insistam mais nessas diferenças epistemológicas. O que tenho a dizer pode não ser interpretado por alguns como a melhor defesa do que eles fazem. Que assim seja. Deixo para aqueles que estão menos em cima do muro que falem mais sobre isso. (No entanto, eu de certa forma falo de etnógrafos ou pesquisadores de campo de maneira indiscriminada, colocando no mesmo saco pessoas que talvez preferissem ficar separadas.)

Muita energia é desperdiçada em detalhes filosóficos, que muitas vezes têm pouco ou mesmo nada a ver com o que os pesquisadores fazem, por isso eu me concentro menos nos enunciados teóricos e mais na maneira pela qual os pesquisadores trabalham tais posições na prática. 0 que os pesquisadores fazem reflete uma certa acomodação às realidades da vida social, o que os afeta da mesma maneira que qualquer outro ator estudado pelos cientistas sociais, já que limita o que eles podem fazer. Assim, sua atividade não pode ser explicada ou justificada por suas posições filosóficas (Platt, trabalho inédito). Em 
suma, estou descrevendo a epistemologia prática, de que maneira o que fazemos afeta a credibilidade das proposições que defendemos. Em geral, acredito (sem surpreender ninguém ao fazê-lo) que os argumentos defendidos pelos pesquisadores qualitativos têm uma grande validade, mas não da maneira dogmática e geral pela qual tais argumentos são muitas vezes defendidos. Então, farei aqui e ali algumas observações arrogantes acerca dos excessos nos quais etnógrafos muitas vezes incorrem.

Algumas questões básicas parecem jazer no cerne destas discussões sobre esses métodos: devemos levar em consideração a perspectiva do ator social e, se for o caso, como devemos fazê-lo? Como lidar com a enraizamento de toda ação social no mundo cotidiano? E, ainda, quão densas devem ser as nossas descrições?

\section{0 ponto de vista do ator: precisão}

Um ponto fundamental que os etnógrafos defendem como sendo uma das maiores vantagens epistemológicas do que eles fazem é que o método permite que se compreenda o ponto de vista do ator. Isso satisfaz o que eles consideram um critério crucial para produzir uma ciência social adequada. "Levar em consideração o ponto de vista do outro" é um ótimo exemplo da variedade de sentidos metodológicos que os slogans adquirem. Para alguns, há aí um certo tipo de significância religiosa ou ética: se não formos capazes de fazê-lo, podemos demonstrar um desrespeito para com as pessoas que estudamos. Outra tendência vai ainda mais longe, criticando a ciência social que "fala" pelos outros, dando resumos e interpretações de seus pontos de vista. Segundo esta visão, não é suficiente honrar, respeitar e aceitar o ponto de vista dos atores; deve-se deixar que eles próprios exprimam seu ponto de vista.

Para outros, entre os quais eu me encaixo, trata-se de uma questão técnica, que é melhor analisada por Herbert Blumer (1969): todos os cientistas sociais, implícita ou explicitamente, atribuem um ponto de vista às pessoas cujas ações estudamos. Isto é, sempre descrevemos como nós interpretamos os eventos nos quais elas participam. Assim, a questão relevante não é se devemos ou não fazê-lo, mas quão precisamente podemos fazê-lo. Podemos descobrir, não com uma precisão exata (mas maior que zero), o que as pessoas pensam que estão fazendo, que significados elas dão aos objetos, eventos e pessoas nas suas vidas e experiências. Fazemos isso por meio de conversas com essas pessoas, em entrevistas informais ou formais, em interações rápidas enquanto participamos e observamos suas atividades ordinárias, e observando e ouvindo enquanto essas pessoas continuam agindo à vontade. Podemos até usar questionários para deixá-los dizer quais significados constroem ou para escolher entre os significados que damos como possibilidade. Para antecipar um ponto mais tardio, quanto mais próximo chegarmos às condições nas quais tais pessoas atribuíram sentido aos objetos e eventos, mais precisas serão as descrições de tais sentidos.

Blumer argumenta que se não descobrirmos por meio das próprias pessoas quais os sentidos que elas dão às coisas, ainda assim vamos falar sobre tais sentidos. Neste caso, vamos inventá-los quando for necessário, raciocinando que as pessoas sobre as quais escrevemos devem ter querido dizer isso ou aquilo, ou elas não teriam feito as coisas da maneira que fizeram. Mas, do ponto de vista epistemológico, é inevitavelmente perigoso fazer adivinhações sobre o que pode ser observado diretamente. O perigo é que podemos adivinhar errado, e o que nos parece razoável pode não ser razoável para aquelas pessoas. Isso acontece frequentemente, em grande medida porque não somos aquelas pessoas e não vivemos nas suas circunstâncias. Assim, estamos sujeitos a pegar o caminho mais fácil e atribuir às pessoas o que achamos, como sentimos e entendemos suas circunstâncias. Como o fazem estudiosos do comportamento adolescente, quando observam as taxas comparativas de gravidez, e as correlações possíveis, e decidem como as pessoas envolvidas "devem ter pensado" para terem agido de tal maneira.

O campo de estudo do uso de drogas, com vários pontos de contato com o campo de estudo da adolescência, é abundante em tais erros de atribuição. O significado mais comumente atribuído ao uso de drogas é que seria uma "fuga" de algum tipo de realidade que o usuário de droga considera opressiva ou insuportável. A intoxicação por drogas é compreendi- 
da como uma experiência na qual todos os aspectos dolorosos e indesejados da realidade seriam ofuscados de forma que não fosse preciso, para o usuário, lidar com eles. $O$ usuário substituiria a realidade por sonhos chamativos de esplendor e desembaraço, prazeres sem problemas, perversas emoções eróticas e fantasias. A realidade é entendida como uma assombração distante, pronta para dominá-lo no momento em que ele ou ela despenque desse mundo etéreo.

Este tipo de imaginário tem uma longa história, provavelmente originária de "Confessions of an English Opium Eater”, de De Quincey (1971). (Uma versão maravilhosa americana deste texto do século XIX é a de Fitz Hugh Ludlow The Hashish Eater [1975]). Essas obras jogam com o imaginário analisado no exame da Orientalia, the Orient as Mysteriuos Other de Edward Said (1978). Versões mais modernas, mais cheias de ficção científica, menos orientais, e mais benignas, podem ser achadas nas obras de William Burroughs, como por exemplo Naked Lunch (Burroughs, 1966).

Estas descrições do uso de drogas são, como tem sido descoberto por gerações de pesquisadores que se preocuparam em fazer perguntas, puras fantasias da parte de pesquisadores que as publicaram. As fantasias não correspondem às experiências dos usuários ou dos pesquisadores que fizeram as experiências eles próprios. Elas estão imersas numa ignorância voluntária.

As interpretações errôneas das experiências e significados são comuns nos estudos sobre delinquência e crime, comportamento sexual, e em geral nos estudos de comportamento alheios à experiência ou estilo de vida dos acadêmicos convencionais. Muito do que os estudos da antropologia e da etnografia trouxeram ao entendimento dos problemas da adolescência e da experiência de crescer é uma correção de simples erros de fatos, substituindo a especulação por observação.

Porém o "não invente o que você pode encontrar" dificilmente precisa ser dignificado como uma posição filosófica ou epistemológica. Não é nem muito diferente de uma compreensão convencional e até mes- mo positivista do método (Lieberson, 1992), sendo apenas, talvez, mais rigorosa e exigindo a verificação da especulação que os pesquisadores não podem se eximir de fazer. Assim, o primeiro ponto é que a epistemologia da etnografia, na sua insistência em investigar o ponto de vista dos que são estudados, é de fato como qualquer outro ponto de vista dos cientistas sociais, só um pouco mais rigoroso e completo. (Eu acho difícil evitar - e não também não me esforço muito para fazê-lo - a ironia de insistir que a pesquisa qualitativa é tipicamente mais precisa e rigorosa que um survey, que é mais comumente visto como tendo uma vantagem nesses critérios).

Uma razão pela qual os pesquisadores que concordariam em tese com esse princípio evitam investigar os pontos de vista dos atores é que as pessoas que estudamos repetidamente não dão significados consistentes às coisas, pessoas e eventos. Elas mudam de opinião frequentemente. $\mathrm{E}$ ainda pior, elas podem muitas vezes não ter certeza do que as coisas significam, fazendo interpretações vagas e confusas de eventos e pessoas. E o que se segue do argumento prévio, é que devemos respeitar tais confusões e a inabilidade de ser decisivo e não dar um significado mais estável do que as pessoas que estão envolvidas dão. Mas fazer isso deixa o trabalho do pesquisador mais difícil, porque é muito mais difícil descrever, quanto mais mensurar, um alvo em movimento.

Um excelente exemplo da instabilidade dos sentidos "nativos" é dado na análise de Bruno Latour (1987) sobre a ciência. Convencionalmente, cientistas sociais dão um status especial ao conhecimento criado pelos cientistas, tratando-o melhor do que o saber convencional dos leigos, por ser mais garantido. Latour ressalta este paradoxo: os próprios cientistas não consideram a ciência sempre dessa maneira. Às vezes eles até o fazem, tratando o resultado como definitivo e "colocando-o numa caixa preta". Mas os cientistas frequentemente discutem entre si, tentando evitar que outros coloquem um resultado numa caixa preta ou, ainda pior, abrindo caixas pretas que todos pensavam estarem fechadas para sempre. Sua regra de método é a seguinte: devemos ser tão indecisos quantos os atores que estudamos. Se eles acham que uma conclusão, uma descoberta ou uma teoria é instável, controversa, ou aberta a questiona- 
mentos, então também devemos achá-lo. E devemos fazer isso mesmo quando o que está sendo estudado seja uma controvérsia histórica cujo desfecho seja agora conhecido, embora os atores envolvidos durante tal período não pudessem prevê-lo. Num sentido contrário, se os atores envolvidos pensam que a ciência envolvida é inquestionável, então também devemos pensar assim.

Pessoas que escrevem sobre ciência de maneira prescritiva - epistemólogos - poderiam evitar distorcer as ideias daqueles que estudam se seguissem as regras que os antropólogos inventaram para as suas pesquisas de campo. Houve um tempo em que se acreditava que visitar uma tribo por um mês ou dois durante o verão era suficiente para conseguir toda informação dos informantes com a ajuda de tradutores. Ninguém mais acredita nisso, e agora há um certo parâmetro mínimo: conhecer completamente a língua nativa, permanecer entre um ano e dezoito meses e usar algum tipo rudimentar de técnicas de amostragem. Essas regras aplicadas ao estudo da ciência demandariam dos epistemólogos que aprendessem plenamente a língua nativa. Não somente a versão "high church" usada apenas em ocasiões formais, mas a linguagem de todos os dias também; não somente a visão dos "eminentes cientistas" e aqueles que falam pela ciência, mas sim dos cientistas comuns que fazem o trabalho. E é exatamente isso que Latour (1987) e outros estudantes da observação da "linha de montagem" ${ }^{4}$ na ciência têm feito (e que Diesing [1971], um epistemólogo não-usual, fez), mas que muitos outros sociólogos da ciência não fizeram.

Dessa forma, epistemologicamente os métodos qualitativos insistem que não devemos inventar a perspectiva do ator, e devemos apenas atribuir aos atores ideias sobre o mundo em que eles de fato acreditem, se queremos entender suas ações, razões e motivos.

\section{0 mundo cotidiano: dando espaço ao inesperado}

Um segundo ponto, semelhante à ênfase na aprendizagem e na compreensão - em vez da invenção

- dos sentidos que as pessoas dão ao seu mundo e

4. NT: Tradução da expressão original "shop floor practice". suas experiências, é a ênfase no mundo de todos os dias, na vida do dia-a-dia, do cotidiano. Essa conhecida e já batida frase aparece frequentemente na escrita etnográfica, muitas vezes se referindo às ideias de Alfred Schutz. Nos escritos de Schutz (1962), e na elaboração dessas ideias comuns entre os etnometodólogos, o mundo cotidiano tipicamente se refere aos entendimentos presumidos que as pessoas compartilham e que fazem com que as ações concertadas sejam possíveis. E dentro disso, a ideia assemelha-se à noção de cultura de Redfield (1941) - "entendimentos compartilhados manifestos no ato e no artefato" - e aos "significados compartilhados" de George Herbert Mead tal como interpretado por Blumer (1969).

A ideia geral é que agimos no mundo com base em presunções que não questionamos, mas que são a base da nossa ação. E que quando agimos estamos certos de que os outros vão reagir da maneira que esperamos. Uma outra versão desta ideia é dizer que as coisas olham para mim como elas olhariam para você se você estivesse posicionado onde estou. Nesta visão, "os entendimentos cotidianos" se referem não tanto às compreensões envolvidas, por exemplo, na análise do sistema de parentesco - que é a maneira em que uma pessoa deve agir, por exemplo, com uma mãe, um irmão ou uma filha - mas às crenças epistemológicas que fundamentam todas essas ideias compartilhadas, as meta-análises e ontologias das quais não estamos sempre cientes e que fazem a vida social possível.

Muito esforço teórico tem sido gasto nesse conceito. Eu prefiro uma interpretação mais simples, menos controversa, mais comum, tanto como uma alternativa ou simplesmente como um complemento para esses significados profundamente teóricos. Esta é a noção do mundo cotidiano como o mundo em que as pessoas de fato agem todos os dias, o mundo comum no qual as coisas em cuja compreensão estamos interessados de fato acontecem. Em oposição a quê? Ao mundo mais simples, menos dispendioso, que os cientistas sociais constroem para gastar menos tempo e coletar dados mais eficazmente, nos quais os questionários das surveys são preenchidos e os documentos oficiais são consultados como plataformas para observações das atividades e eventos aos quais se referem. 
A maior parte dos etnógrafos pensa que está chegando mais perto da coisa real do que em outros tipos de pesquisa, pela própria virtude de se observar o comportamento in situ ou ao menos deixar que as pessoas contem o que lhes aconteceu nas suas próprias palavras. Claramente, sempre que um cientista social está presente, a situação não é apenas aquela que seria se este pesquisador não estivesse presente. Eu suponho que isso também se aplica mesmo quando ninguém sabe que aquela pessoa é um cientista social fazendo uma pesquisa. Um novo membro de um culto que acredita em discos voadores de outros planetas e na proximidade de sua chegada é, de qualquer maneira, mais um membro do culto que não fazia parte dele até então. E se esse culto for pequeno demais, isso já aumentaria o número de pessoas, o que poderia afetar aquilo que observador está lá para estudar.

Em suma, como a situação não é nunca exatamente como seria caso o pesquisador não estivesse lá, há níveis de interferência e influência. Etnógrafos se orgulham de observar e ouvir, mais ou menos, o que as pessoas fariam e diriam se os observadores não estivessem lá.

Uma razão para se supor que isso seja verdade é que os etnógrafos observam as pessoas enquanto todas as restrições da vida social ordinária estão em operação. Vamos considerar isso comparativamente. Usualmente, asseguramos às pessoas que entrevistamos, ou às quais pedimos para responder questionários, que ninguém nunca vai saber o que eles nos disseram, ou o que assinalaram no questionário. (Se não tivermos certeza de que podemos assegurar tal confidencialidade, geralmente nos preocupamos com a validade dos resultados.) Isso isola as pessoas entrevistadas das consequências que eles poderiam sofrer caso outras pessoas conhecessem suas opiniões. Este isolamento nos ajuda a descobrir os pensamentos privados das pessoas, as coisas que estas pessoas escondem de seus colegas, o que é geralmente o que queremos descobrir.

Porém não devemos tirar a conclusão precipitada de que a expressão deste pensamento privado determina as ações desta pessoa numa situação na qual tal pensamento pode ser relevante. Quando obser- vamos pessoas agirem onde elas geralmente agem (isto é, quando as observamos no seu ambiente de trabalho, ou quando elas vão até uma reunião política no seu bairro, ou ainda quando jantam com a sua família), não podemos isolá-las das consequências das suas próprias ações. Pelo contrário, as pessoas têm que aceitar as consequências do que fazem, exatamente como fariam na sua vida cotidiana. Um exemplo: quando estava observando estudantes de graduação, eu algumas vezes ia com eles para as aulas. Numa ocasião, o instrutor anunciou que haveria uma prova surpresa para a qual o estudante que eu estava acompanhando, um fanfarrão, estava totalmente despreparado. Sentado ao lado dele, eu podia facilmente ver que ele estava se inclinando e copiando as repostas de outra pessoa que ele imaginava saber mais do que ele. Ele ficou com vergonha de eu ter percebido o que ele fez, mas tal vergonha não o impediu de continuar "colando", porque as consequências de ir mal no teste (isto aconteceu durante o período no qual ser jubilado da universidade, o que poderia levá-lo a ser convocado a servir no exército e a ser morto em combate) eram bem piores do que uma queda potencial da minha opinião sobre. Ele se desculpou e deu alguns pretextos para suas ações, mas ele de fato "colou" na prova. O que será que ele diria sobre ter "colado" num questionário ou numa entrevista, totalmente fora da situação na qual ele foi forçado a tomar tal atitude?

Nossas opiniões ou ações não são sempre vistas como não tendo consequências pelas pessoas que estudamos. Cientistas sociais que estudam escolas e agências sociais muitas vezes descobre que os funcionários dessas organizações veem a pesquisa como uma versão das avaliações institucionais às quais são sempre submetidos, e por isso tomam medidas para manipular o que pode ser descoberto. Algumas vezes, as pessoas mais fáceis de serem entrevistadas são aquelas que estão mais por fora da sociedade ou cultura local, desejando de fato uma saída e contando com a ajuda do etnógrafo para tanto. Todavia, mesmo que essas exceções à regra geral devam ser sempre analisadas com cuidado, geralmente os etnógrafos defendem o ponto a seguir como argumento epistemológico fundamental: quando eles falam sobre o que as pessoas fazem, eles falam sobre o que viram tais pessoas fazer sob certas condições 
que normalmente estão presentes, em vez de fazer inferências a partir de um indicador mais remoto (tal como a resposta a uma pergunta na privacidade de uma conversa com um estranho). Eles estão vendo "o mundo real" da vida cotidiana, não uma versão criada a pedido e para o benefício deles (etnógrafos). E essa versão do "mundo real", acreditam eles, merece ser tratada com um valor de verdade maior do que as versões potencialmente menos precisas produzidas por outros métodos, não importando quais sejam as vantagens de eficiência ou de diminuição de custos dessas outras técnicas.

A consequência de se descobrir os detalhes da vida cotidiana é que muitos eventos e ações acabam tendo explicações prosaicas, que raramente são levadas em consideração nas nossas teorias. Um estudante num curso sobre pesquisa de campo que eu dei na cidade de Kansas estudou carteiros. Sob a minha orientação, ele tentou descobrir que tipos de rotas eram preferidas pelos carteiros: que partes da cidade eles escolhiam trabalhar quando eles tinham a opção de escolher? Tendo feito tal pesquisa, ele convidou seus colegas a adivinhar a resposta e os seus colegas, como nascentes cientistas sociais que eram, imaginaram que as respostas seriam centradas nas classes sociais. Os carteiros prefeririam as áreas de classe média, porque tais áreas seriam mais seguras; eles também prefeririam as áreas de classe operária, porque seus habitantes estariam em menos listas de endereços e por isso haveria menos cartas a serem entregues. Todas essas repostas parecem muito astutas, mas esses "chutes" razoáveis estavam todos errados. Kansas City é cheia de morros e por isso os carteiros preferiam não ter que subir e descer os morros enquanto eles entregavam o correio. Esta é uma explicação que não faz sentido do ponto de vista da "estratificação"; um seguidor de Bourdieu, por exemplo, não incluiria tal item no seu survey. Mas essa foi a razão que os carteiros deram, uma razão costumeira, que estava esperando ser descoberta por alguém que deixasse espaço para que ela pudesse aparecer.

\section{Descrição completa, descrição densa: observando as margens}

Etnógrafos se orgulham de proporcionarem descrições densas e detalhadas da vida social, o tipo de coisa que Geertz (1974) nos ensinou a reconhecer como "espessas" ou densas. O orgulho deles implica que quanto mais completa for a descrição, melhor, sem nenhum limite sugerido. No extremo, etnógrafos falam de reproduzir as "experiências vividas" pelos outros.

Existe algo errado com isso na sua superfície. O objeto de qualquer descrição é não reproduzir o objeto completamente - por que fazer isso se já temos o objeto? - mas sim ressaltar seus aspectos relevantes, detalhes que podem ser abstraídos da totalidade dos detalhes e que nos ajudam a responder algumas questões. Cientistas sociais, por exemplo, se concentram no que pode ser descrito por palavras ou números, e assim deixam de fora todos os outros aspectos da realidade que lidam com os outros sentidos, por exemplo, o que pode ser visto, ouvido e cheirado. (Quantas monografias lidam com o cheiro daquilo que está sendo estudado, mesmo quando o odor é um componente necessário e interessante [e quando não o é?]? [Becker, 1986, p. 121-135].)

Etnógrafos geralmente ressaltam o "avanço" do método que permite a inclusão de um maior número de detalhes: fotografias, gravações de áudio, gravações de vídeo. Esses avanços nunca nos levam muito longe dentro do objetivo da descrição plena; a realidade completa ainda está um longo caminho à frente. Mesmo quando preparamos a câmera de vídeo para filmar, ela fica num lugar durante um tempo, e algumas coisas não podem ser vistas daquele ponto de vista; acrescentar outras câmeras não muda o argumento. Mesmo um aspecto técnico como a distância focal da lente da câmera faz uma grande diferença: uma lente longa fornece o detalhe do close-up, mas perde o contexto que a lente mais aberta nos fornece.

Portanto, a descrição completa é ilusória. Todavia, a descrição densa é preferível, e epistemologicamente mais recompensadora, que uma descrição escassa. Por quê? Porque, assim como no argumento sobre o ponto de vista do ator, ela nos permite falar com mais segurança sobre as coisas do que se tivéssemos que inventá-las - e, para repetir, são raros os cientistas sociais que são suficientemente disciplinados a ponto de evitar inventar interpretações e detalhes que não tenham, de uma maneira ou outra, observado. 
Pensemos num exemplo simples. Suponhamos que desejemos saber se as ocupações dos pais afetam as escolhas de emprego que os adolescentes fazem. Nós podemos tentar descobrir isso incluindo uma linha sobre a ocupação dos pais numa pergunta de um questionário. Podemos também copiar o que os pais escreveram em algum lugar, talvez num documento escolar. Podemos ainda ir até onde os pais trabalham e verificar, através da nossa própria observação, que um deles ensina numa escola, outro dirige um ônibus e um terceiro trabalha numa agência de publicidade. Algum desses procedimentos é melhor do que os outros? Pedir para que os filhos escrevam a ocupação dos pais num formulário é mais barato e eficiente. Copiar a profissão dos pais de um documento escolar pode ser melhor, porque os pais têm um melhor conhecimento do que eles fazem e uma melhor linguagem para expressá-lo do que as crianças. A observação feita por nós próprios ainda estaria aberta a questionamentos - talvez os pais só estivessem trabalhando em determinado local durante aquela semana -, mas este tipo de método deixa menos espaço para que se cometa um deslize; não precisamos nos preocupar com a ignorância da criança ou com o desejo dos pais de inflar seu status. Epistemologicamente, eu penso que a observação exige menos inferência e menos presunções e, por isso, tem mais chance de ser precisa, mesmo que tal precisão não seja necessária.

Um objetivo melhor que a "densidade", geralmente almejada por um pesquisador de campo, é a "amplitude": tentando descobrir algo sobre todos os tópicos que são abarcados pela pesquisa, mesmo que tangencialmente. Nós queremos saber algo sobre a vizinhança em que moram os jovens delinquentes que estudamos, sobre as escolas que frequentam, sobre as delegacias e prisões em que ficam, e sobre uma dúzia de outras coisas. Os pesquisadores de campo apreendem muitas informações incidentais sobre tais aspectos durante suas interações com o campo ou longas entrevistas. Porém, assim como os pesquisadores quantitativos, eles geralmente usam "os dados disponíveis" para se ter alguma ideia sobre tais informações. No entanto, eles o fazem com um ceticismo maior do que o usual.

É hora de mencionar, brevemente, o aspecto já co- nhecido das "estatísticas oficiais" ou, para colocar em termos mais gerais, a necessidade de se questionar a maneira pela qual os dados são mantidos, quem faz isso, e como isso pode afetar esses dados. (Nada disso é novidade para os historiadores, que veriam aí simplesmente uma questão sobre a quais críticas as fontes que eles usam deveriam ser submetidas). Como Bittner e Garfinkel (1967) nos ensinaram anos atrás, as organizações não mantêm dados para que os cientistas sociais os tenham, mas sim por seus próprios motivos. Isso é bastante óbvio no caso dos adolescentes, no qual sabemos que os dados sobre a frequência escolar são "geridos" pelas escolas com o objetivo de aumentar as verbas públicas recebidas; que os registros sobre o comportamento dos alunos são manipulados para justificar ações tomadas em relação a alunos difíceis; que os resultados de provas são manipulados para justificar o rastreamento e a perseguição. Da mesma forma, os registros policiais são mantidos por motivos de polícia, e não para serem objetos de testes de hipóteses de pesquisadores.

Etnógrafos, dessa forma, tipicamente tratam dados recolhidos por autoridades e similares como dados sobre o que tais pessoas fizeram: estatísticas de polícia como dados sobre como a polícia mantém seus dados e o que eles fazem com tais dados, registros sobre os exames escolares como dados sobre o que as escolas e os examinadores fazem em vez de dados sobre as características dos alunos, e assim vai. Isso significa que os etnógrafos são tipicamente muito mais irreverentes e isso causa problemas.

Isso causa problemas nos casos em que outras pessoas não compartilham tal irreverência, e ao invés disso levam as instituições a sério nos seus próprios termos. Pesquisadores qualitativos estão muitas vezes, mas não necessariamente sempre, numa relação antagônica com as fontes de dados oficiais, mas estes não gostam de serem tratados como objeto de estudo; querem, sim, ser acreditados (Discuti isso em outro texto (Becker, 1967) dentro do tema da "hierarquia da credibilidade").

\section{Epílogo}

Não há muito mais a ser dito. Praticantes de pesquisa qualitativa e quantitativa podem parecer ter dife- 
rentes filosofias de ciência, mas na verdade eles só trabalham em situações diferentes e fazem perguntas diferentes. A política da ciência social pode nos seduzir a aumentar tais diferenças. Não precisamos fazê-lo e não devemos fazê-lo.

\section{Considerações adicionais}

Depois das discussões que ocorreram nesta conferência, algumas pessoas sentiram que ainda havia questões não resolvidas de que eu deveria tratar. Estas não foram as questões que são geralmente levantadas e as minhas respostas não foram mesmo "respostas", mas sim reações em que discuti o ambiente social no qual tais questões são colocadas mais do que os meus interlocutores poderiam ter antecipado.

Uma questão diz respeito a como seria possível juntar o que é algumas vezes se chama de "duas modalidades", as perspectivas qualitativa e quantitativa na pesquisa social. Não há quase literatura nesta questão, o que acaba geralmente sugerindo uma divisão do trabalho, na qual a pesquisa qualitativa gera hipóteses e a pesquisa quantitativa as testa. Essa questão é invariavelmente levantada, e tal solução é proposta por pesquisadores quantitativos que parecem achar que isso é um grande problema, e nunca por pesquisadores qualitativos, que geralmente seguem em frente, sem ver aí um grande problema, seguindo a linha de Robert E. Park, como eu sugiro neste artigo.

Nesse sentido, por que os pesquisadores qualitativos não veem isso como um problema? Eles não veem isso como um problema porque eles se concentram nas questões a serem respondidas em vez dos procedimentos a serem observados. A lógica disso é mostrada com enormes detalhes num livro não tem nada de sociologia, o Mathematics and Plausible Reasoning (1954), de George Polya, no qual ele mostra como combinar informações de todos os tipos para avaliar a razoabilidade de uma conclusão ou ideia.

E como os pesquisadores de fato fazem para combinar esses tipos diferentes de dados? Esse não é um assunto fácil de ser resumido, porque pesquisadores qualitativos têm feito isso há muito tempo, e há muitos exemplos disso sendo feito em muitas partes da literatura da área. Thomas Kuhn (1970) observou que cientistas aprendem o seu ofício não por seguir receitas abstratas de procedimento, mas sim por meio de estudo de trabalhos em suas áreas tidos como extraordinários. A melhor maneira de ver como os diferentes tipos de dados são combinados é por meio de trabalhos exemplares. Não pude me estender sobre a questão, que é obviamente demasiado ampla para um artigo de conferência.

Todavia, cito três trabalhos bem conhecidos, e sugiro a análise dos métodos usados por eles em outros trabalhos que podem ser realizados por aqueles que desejem responder a tal questão. Horace Cayton e St. Clair Drake desenvolveram um monumental estudo das áreas negras do South Side de Chicago em Black Metropolis (1945) no final dos anos de 1930. Tal estudo contém dados de todos os tipos imagináveis, alguns estatísticos, alguns de observação, todos direcionados para responder questões sobre a organização daquela comunidade. Boys in White (1961) é uma pesquisa sobre os estudantes de medicina conduzida por vários de nós no final dos anos de 1950, que se baseou na observação e em entrevistas não-estruturadas para produzir dados, mas os dados foram apresentados tanto de uma forma etnográfica quanto em tabelas simples que foram, para a surpresa dos fanáticos qualitativos, "quantitativas". Ainda que não tivéssemos usado nenhum teste de significância, as diferenças que apontamos eram grandes o suficiente, de forma que tais testes foram desnecessários. O trabalho de Jane Mercer, Labeling the Mentally Retarded (1973), é o mais próximo dos três à típica combinação recomendada; ela usou tanto surveys da comunidade e registros oficiais de vários tipos quanto entrevistas não-estruturadas para chegar às suas conclusões sobre o caráter social do retardamento mental.

A segunda indagação lida com a "validade", lembrando que o meu artigo não lida com essa questão, mas em vez disso discutiu (seguindo a liderança de Polya, 1954) a questão de credibilidade. Será que acredito mesmo que tudo o que importa em matéria de validade é produzir um caso plausível? Será que não há algo a mais envolvido, especialmente, o grau em que alguém observou ou mensurou o fenômeno com o qual diz lidar (em oposição àquela preocupação sobre se dois observadores poderiam chegar ou não 
ao mesmo resultado, que foi uma das maneiras pela qual algumas pessoas interpretaram a minha análise da credibilidade)?

Chegamos aqui a uma diferença que é uma questão não de lógica ou de prática científica, mas de organização profissional, de comunidade, e de cultura. A comunidade profissional na qual o trabalho quantitativo é realizado (e eu acredito que isso é mais verdade na psicologia do que na sociologia) insiste em colocar algumas questões sobre confiabilidade e validade, e transforma as boas respostas a essas questões no critério fundamental (touchstone) de avaliação de um bom trabalho. No entanto, há outras comunidades profissionais nas quais estas questões não são fundamentais para seus operadores. Pesquisadores qualitativos, especialmente em sociologia e antropologia, estão mais propensos a se preocuparem com os tipos de questões que eu levantei no corpo deste artigo: se os dados são precisos, no sentido de serem baseados na observação do que está sendo discutido ou apenas nos indicativos remotos; se os dados são precisos, no sentido de serem próximos daquilo discutido e por isso estão prontos a lidar com questões não antecipadas na formulação original deste problema; se esta é uma análise completa ou ampla, no sentido de conhecer um largo número de temas que afetam a questão sendo estudada, e não apenas algumas variáveis. Este artigo contém um número relevante de exemplos desses critérios.

Normalmente, as comunidades acadêmicas não entram nos territórios umas das outras, e por isso não têm que responder aos critérios umas das áreas. Ao operar dentro de um paradigma aceito na sua comunidade, cientistas sociais fazem o que seus colegas consideram aceitável, sabendo que eles vão ter que prestar contas à sua comunidade caso não sigam tais critérios. Quando, porém, duas (ou ao menos duas, talvez mais) comunidades acadêmicas se encontram, como aconteceu nesta conferência, a questão que aflora é a de saber em qual dessas linguagens a nossa discussão será conduzida, e quais parâmetros serão usados. Observei ao longo dos anos que pesquisadores quantitativos insistiam em saber quais respostas os pesquisadores qualitativos tinham às suas (dos pesquisadores quantitativos) questões sobre validade, confiabilidade e testes de hipóteses. Eles, quanti- tativistas, não discutiam no entanto como poderiam responder às questões que pesquisadores qualitativos levantavam sobre exatidão, precisão e amplitude. Em outras palavras, eles queriam assimilar o que outros faziam, mas à sua própria maneira, e ainda levar os outros (qualitativistas) a responder às suas próprias questões (dos quantativistas). Eles queriam que a discussão fosse conduzida dentro da sua própria linguagem e que os parâmetros do trabalho qualitativo fosse traduzido numa linguagem que eles já utilizam.

Este desejo - poderia dizer insistência - presume que há um status diferencial: "A" pode denunciar "B" por não responder adequadamente as questões postas por "A", mas "B" não tem a mesma obrigação para com "A". No entanto, esta é uma afirmação sobre uma organização social, não sobre epistemologia. É uma afirmação sobre poder em sistemas hierárquicos, não sobre lógica. Quando, porém, as comunidades acadêmicas operam independentemente, em vez de estarem organizadas numa hierarquia de poder e obrigação, como é presentemente o caso de diferentes tipos de ciência social, os membros não precisam usar a linguagem de outros grupos; eles usam a sua própria linguagem. As relações entre os grupos são horizontais, e não verticais, para usar uma metáfora espacial. Uma comunidade não está numa posição de exigir que a outra use a sua linguagem.

Isso tem acontecido de certa forma nas ciências sociais. O crescimento da ciência social (observe que este argumento tem uma base demográfica) tornou possível que subgrupos possam constituir seus próprios mundos, com suas próprias revistas, organizações, presidentes, prêmios, e toda tipo de parafernália de uma disciplina científica.

Será que isso significa que eu esteja aqui reduzindo ciência a aspectos de demografia e de importância política? Não, significa que esta é uma versão a mais sobre um problema padrão nas relações entre grupos culturalmente diversos. Para evidenciar este ponto, as analogias aos problemas de tradução entre diferentes linguagens e culturas (muito bem analisados, por exemplo, no artigo de Talal Asad (1986), "The Concept of Cultural Translation in British Social Anthropology”) são exemplos que nos ajudam. Gru- 
pos dominantes em situações de contato cultural (e.g. situações coloniais) geralmente pensam que tudo deva ser traduzido para que assim faça sentido em sua linguagem, em vez de serem traduzidos de forma que a plenitude da diferença cultural contida nos conceitos seja mantida nas traduções. Eles geralmente têm poder suficiente, ao menos por algum tempo, para exigir que isso seja feito.

O problema da tradução entre grupos culturalmente diversos é o mesmo para o qual Kuhn (1970) chamou em relação a casos de diferença substancial de paradigma (como no caso de mudança de paradigma): as linguagens nas quais os trabalhos científicos são realizados não podem ser traduzidas umas para as outras. Se os grupos são de fato independentes, então há um problema de tradução e a mesma dinâmica (de quais categorias serão respeitadas) se torna relevante.

Portanto, o que parecem ser exigências razoáveis para algum esclarecimento é, na verdade, a reencenação de um conhecido ritual. É o que ocorre sempre que pesquisadores quantitativos em educação, psicologia, e sociologia decidem que eles devem prestar atenção aos trabalhos de outros tipos de pesquisa e depois tentar cooptar estes trabalhos para fazê-los responder aos seus critérios, critérios como confiabilidade e validade, em vez dos critérios que mencionei aqui, rotineiramente utilizados por pesquisadores qualitativos. Eu diria que não é que eu não estivesse lidando com questões de validade, mas que eu estava lidando com outras questões que me parecem tão fundamentais quanto são as questões de validade para outros pesquisadores.

Isso pode parecer estar em contradição com minha convicção fundamental, que expus neste artigo, que estes dois tipos de trabalho de fato compartilham a mesma, ou muito semelhante, epistemologia. Eu ainda acredito que isso seja verdade. Mas também acho que alguns pesquisadores ficam obcecados com alguns tipos específicos de procedimentos (que não são a mesma coisa que epistemologia), e acabam agindo como descrevi: eles entendem que outros tipos de trabalho devem ser justificados em referência àqueles procedimentos pelos quais eles têm fixação.
Finalmente, algumas pessoas perguntaram como podemos diferenciar o bom do ruim, ou o melhor do pior no trabalho qualitativo. Eu já havia sugerido uma resposta nos critérios discutidos. $O$ trabalho que é baseado numa observação de perto e cuidadosa de aspectos variados que são relevantes para a questão que está sendo investigada é melhor do que um trabalho que se baseia na inferência e em outras formas mais remotas de observação. Este é um critério. Uma das razões pelas quais o trabalho Street Corner Society (Whyte, 1981) é largamente reconhecido como uma obra-prima da ciência social é porque ele satisfaz esse critério mencionado. William Foote Whyte conhecia aquilo de que falava. Ele tinha observado durante um tempo longo a organização social que analisou em detalhes minuciosos. E ele não observou apenas as interações entre alguns meninos da "esquina”, mas sim também a operação de organizações muito mais amplas da política e do crime, que acabavam afetando a vida daqueles meninos da esquina.

Entretanto, algo a mais precisa ser dito. Muitas pessoas que reconhecem facilmente a qualidade do trabalho de Whyte ou os estudos de Erving Goffman sobre organização social, também são mais rápidas ainda em achar que este tipo de estudo só pode ser feito por pessoas talentosas, e somente estas pessoas poderiam conseguir resultados tão notáveis e, assim, os métodos que eles utilizaram não seriam adequados para o desenvolvimento de uma ciência. Isto reconhece o que deve ser reconhecido - qualidade que todo mundo sabe que existe - enquanto marginalizam o empreendimento que possibilitou tal qualidade possível. Goffman era de fato um cientista social muito talentoso, mas seus talentos foram expressos dentro de uma tradição de pensamento e de pesquisa de campo que vem desde de Durkheim até Radcliffe-Brown e Lloyd Warner, assim como Simmel até Park e Hughes e Blumer. Esta é a tradição que possibilitou este tipo de trabalho.

Todavia, isso é verdade em todos os ramos da ciência social, qualitativas ou quantitativas. Stanley Lieberson, por exemplo, é um talentoso pesquisador quantitativo, mas o que faz com que o trabalho dele seja excepcional não é o fato de ele usar um método particular ou de seguir os procedimentos aprovados corretamente. O trabalho dele é excepcional 
porque ele tem imaginação, porque consegue farejar um bom problema e sabe achar uma maneira de estudá-lo. Tudo isso para dizer que diferenciar o bom do ruim não é tão simples quanto parece. É suficientemente simples saber quando um trabalho é mal feito, e também dizer como ele foi mal feito, e onde ele saiu dos trilhos. Mas isso não significa que é possível, em qualquer versão da ciência social, escrever uma receita de como fazer um trabalho da mais alta qualidade, trabalho que vai além do mero ofício. Isso é uma outra história. Físicos, que tantos cientistas sociais tentam imitar, sabem disso. Por que nós não sabemos?

Portanto, estes assuntos são mais profundos do que parecem, em muitos aspectos, sobretudo (acredito eu), no organizacional. Não respondi, por razões que espero ter deixado claro, às questões que me foram apresentadas da maneira que as pessoas esperavam que eu respondesse. Expliquei essas coisas nos meus termos, e imagino que terão que fazer a tradução.

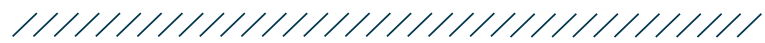




\section{Referências}

Abbott, A. (1992). What do cases do? Some notes on activity in sociological analysis. In C. C. Ragin \& H. S. Becker (Eds.). What Is A Case? Exploring the Foundations of Social Inquiry (p. 53-82). New York: Cambridge University Press.

Asad, T. (1986). The Concept of Cultural Translation in British Social Anthropology. In J. Clifford \& G. E. Marcus (Eds.). Writing Culture: The Poetics and Politics of Ethnography (p.141-164). Berkeley: University of California Press.

Becker, H. S. (1967). Whose Side Are We On? Social Problems 14 (Winter), 239-247.

Becker, H. S. (1982). Art Worlds. Berkeley: University of California Press.

Becker, H. S. (1986). Doing Things Together. Evanston: Northwestern University Press.

Becker, H. S.; Geer, B.; Hughes, E. C. \& Strauss, A. L. (1961). Boys in White: Student Culture in Medical School. Chicago: University of Chicago Press.

Bittner, E. \& Garfinkel H. (1967). 'Good' Organizational Reasons for 'Bad' Organizational Records. In H. Garfinkel (Ed.). Studies in Ethnomethodology. Englewood Cliffs, NJ: Prentice-Hall.

Blumer, H. (1969). Symbolic Interactionism. Englewood Cliffs, NJ: Prentice-Hall.

Burroughs, W. (1966). Naked Lunch. New York: Grove Press.

De Quincey, T. (1971). Confessions of an English Opium Eater. Aletha Hayter (Ed.). Harmondsworth: Penguin.

Diesing, P. (1971). Patterns of Discovery in the Social Sciences. Chicago: Aldine-Atherton.

Drake, S. C. \& Cayton, H. (1945). Black Metropolis. New York: Harcourt, Brace and Co.

Geertz, C. (1974). The Interpretation of Cultures. New York: Basic Books.

Kuhn, T. (1970). The Structure of Scientific Revolutions (2 ed). Chicago: University of Chicago Press.

Latour, B. (1987). Science in Action. Cambridge: Harvard University Press.

Lieberson, S. (1992). Einstein, Renoir, and Greeley: Some Thoughts About Evidence in Sociology. American Sociological Review, 57, 1-15.

Ludlow, F. H. (1975). The Hashish Eater. M. Horowitz (Ed). San Francisco: Level Press.

Mercer, J. (1973). Labeling the Mentally Retarded. Berkeley: University of California Press.
Peneff, J. (1988). The Observers Observed: French Survey Researchers at Work. Social Problems, 35, 520-535.

Platt, J. (artigo inédito). Theory and Practice in the Development of Sociological Methodology.

Polya, G. (1954). Mathematics and Plausible Reasoning. Princeton: Princeton University Press.

Redfield, R. (1941). The Folk Culture of Yucatan. Chicago: University of Chicago Press.

Said, E. (1978). Orientalism. New York: Pantheon.

Schutz, A. (1962). Collected Papers: Volume I, The Problem of Social Reality. The Hague: M. Nijhoff.

Whyte, W. F. (1981). Street Corner Society: The Social Structure of an Italian Slum (3 ed). Chicago: University of Chicago Press. 